\title{
Os limites do poder negocial da França na UE: o caso da União para o Mediterrâneo
}

\author{
The limits of France's negotiating power in the EU: \\ the case of the Union for the Mediterranean
}

MARIA HELENA GUIMARÃES*

Rev. Bras. Polít. Int. 55 (1): 93-105 [2012]

\section{Introdução}

O poder negocial de um Estado-membro da União Europeia (UE) pode ser definido como a sua capacidade para atingir o resultado negocial que reflete de forma tão aproximada quanto possível as suas preferências e interesses. As concepções de poder negocial dos Estados-membros da UE partem, normalmente, da distinção simplista entre Estados grandes e Estados pequenos, em que os primeiros teriam necessariamente mais poder negocial e maior capacidade para influenciar os resultados negociais do que os segundos. No entanto, o poder negocial dos Estados-membros da UE resulta da combinação de vários fatores, pelo que a sua influência sobre os resultados das negociaçôes nem sempre reflete a referida distinção.

A partir de uma breve análise às fontes de poder negocial dos Estadosmembros da UE, sustentamos a hipótese de que os "grandes" Estados, embora concentrem em si várias das fontes de poder negocial, não devem exorbitar desses poderes, pois prejudicam significativamente a obtenção de resultados negociais próximos dos interesses que inicialmente definiram. Para tal elaboramos um estudo de caso referente à iniciativa da França, em 2007, de criação da União do Mediterrâneo $^{1}$. Do estudo conclui-se que, apesar de a França possuir vários dos mais significativos recursos de poder negocial, a sua proposta inicial de criação dessa União com os países da orla sul do Mediterrâneo excedia de tal forma os designados pontos de resistência à negociação (Odell 2001; Woolcock 2003) dos restantes Estados-membros que a iniciativa teve de ser profundamente reformulada. A França sobre-estendeu, ou seja, sobre-exerceu o seu poder negocial e, no final do

\footnotetext{
* Professora Associada da Universidade do Minho (Portugal), Doutora em Ciência Política pela Universidade de Cincinatti, EUA (guimarmh@eeg.uminho.pt).

1 Destaque da autora.
} 
processo de negociação, pouco restava da sua proposta inicial. Assim, a proposição que defendemos é que o poder negocial dos grandes Estados na UE não é ilimitado e o seu exercício não deve ser exorbitado, sob pena de um Estado não conseguir aproximar os resultados negociais dos interesses que pretendia ver satisfeitos.

A presente reflexão inicia-se com uma análise sucinta às fontes de poder negocial na União Europeia. Na segunda seção apresenta-se o projeto de União do Mediterrâneo tal como proposto pela França, e na terceira seção analisam-se as reações dos Estados-membros da UE à proposta francesa. A quarta seção identifica as significativas concessões que a França se viu constrangida a fazer, apesar dos seus recursos de poder negocial na UE. Conclui-se com a avaliação dos resultados do processo de negociaçôes formais e informais entre a França e os restantes Estadosmembros, à luz da contribuição teórica de Tallberg (2008) sobre os recursos de poder dos Estados-membros da UE.

\section{Fontes de poder negocial na UE}

Segundo Tallberg (2008), num artigo de referência, a capacidade negocial dos Estados no Conselho Europeu pode advir fundamentalmente de três fontes: do poder do Estado, do poder de caráter institucional e do poder individual dos chefes de Estado ou de governo. Trata-se de um conceito que relaciona dimensóes diferenciadas, de nível micro, meso e macro, mas complementares na definição e projeção de poder dos Estados.

O poder de um Estado na União Europeia provém fundamentalmente de duas origens: do poder estrutural agregado e do poder específico ao assunto em negociação. Segundo Habeeb (1988), o poder estrutural agregado decorre, na tradição da escola realista, do conjunto de recursos e capacidades de um Estado. Inclui dimensões geográficas (território), demográficas (população) e econômicas (Produto Interno Bruto), mas também a capacidade militar, a estabilidade política do país, a qualidade da sua administração e o grau de desenvolvimento tecnológico, entre outras dimensões. É o conjunto global dessas múltiplas dimensões que está na base dessa fonte de poder negocial. Ceteris paribus, maior poder estrutural agregado permite a um Estado-membro afetar mais recursos e deter mais capacidade e alternativas para influenciar o resultado da negociação, ou seja, para exercer esse tipo de poder. A França é um exemplo paradigmático de país com forte poder estrutural agregado, pelo que possui manifesta capacidade de influência sobre os resultados das negociações na União Europeia e para fazer com que eles se situem próximos dos seus interesses e preferências.

Uma outra dimensão de poder negocial de um Estado é o poder específico no assunto em negociação. Este refere-se ao interesse atribuído e ao empenhamento do Estado na negociação de determinada matéria. Quanto maior o interesse por um assunto ou matéria, mais recursos o Estado devota à sua negociação (por exemplo, 
avançando com iniciativas e propostas), o que se reflete na sua maior capacidade para influenciar os resultados negociais. Assim, em determinados contextos, Estados com menor poder estrutural agregado podem, em assuntos específicos, ter mais poder negocial do que Estados que detêm maior poder estrutural. Em outros casos, como o que é objeto desta análise, ao poder estrutural agregado acresce o poder específico no assunto. A França, além de ter fortes recursos de poder estrutural, tem interesses vastos na área do Mediterrâneo. Tem fortes laços históricos e culturais com os países da região, tem nela interesses econômicos significativos, e acumulou uma larga experiência de relacionamento e um acervo de conhecimento sobre a zona, que explicam o seu grande empenhamento e capacidade de influência em negociações relativas ao Mediterrâneo. A iniciativa de criação da União do Mediterrâneo ilustra, pois, o poder específico da França nas matérias relativas a essa região.

Tallberg (2008) considera ainda que o poder negocial dos Estados no Conselho Europeu depende de fatores institucionais, nomeadamente do exercício da presidência ${ }^{2}$ e do poder de veto. ${ }^{3}$ A presidência, tal como se configurava à data dessa iniciativa da França para o Mediterrâneo, é uma plataforma de poder que confere uma oportunidade única de exercício de poder negocial na União Europeia, em particular aos Estados menores. $\mathrm{O}$ país que detém a presidência dispõe de condiçôes privilegiadas que lhe permitem aumentar o seu poder negocial e fazer aproximar decisões finais dos interesses do seu país. Uma dessas condiçôes privilegiadas é a possibilidade de influenciar a agenda da negociação. É a presidência que mais facilmente introduz na agenda assuntos de interesse do seu país, que a prepara e estrutura, podendo assim conferir maior ou menor peso às matérias a negociar. A influência sobre a agenda é grande, sobretudo na fase preparatória do exercício, podendo ser até mais significativa do que quando o processo negocial formal se inicia. Uma segunda forma ou instrumento que as presidências detêm para aumentar o seu poder negocial é o acesso privilegiado a informação. Essa informação assimétrica detida pela presidência decorre principalmente (1) dos encontros bilaterais com os chefes de Estado e governo (volta às capitais e os chamados confessionários) em que a presidência, muitas vezes antecedendo os processos negociais formais, procura conhecer as preferências e pontos de resistência negociais dos restantes Estados-membros, e decorre ainda (2) do acesso facilitado da presidência a informaçôes e caráter técnico e especializado que lhe são transmitidas pelo Secretariado do Conselho (que apoia a presidência) e pela própria Comissão. ${ }^{4}$

2 Reportamo-nos ao exercício das presidências rotativas semestrais do Conselho Europeu, antes da entrada em vigor do Tratado de Lisboa em $1^{\circ}$ de dezembro de 2009.

3 No presente estudo de caso, dada a matéria em causa não estar sujeita a votação por unanimidade, apenas é pertinente considerar o poder que advém do exercício da presidência.

4 Um outro instrumento da presidência refere-se à sua capacidade para controlar as decisōes sobre a sequência, frequência, formato e método das negociaçôes. São os presidentes que abrem e fecham as reuniōes, forjam os compromissos, decidem do direito à palavra, conduzem os procedimentos de votação, fazem a síntese dos resultados e conclusões. 
Esses instrumentos institucionais de poder da presidência são determinantes para a construção dos entendimentos, sobretudo nos assuntos mais controversos. A França, no entanto, ao colocar na agenda da sua presidência a criação de uma União do Mediterrâneo, fê-lo nos meses que antecederam o seu mandato na presidência da UE, mas negligenciou os contatos prévios com os restantes Estadosmembros e com a própria Comissão.

Finalmente, segundo Tallberg, a terceira fonte de poder negocial na UE é o poder individual do negociador, ou seja, do chefe de Estado ou de governo, ou de Estado que exerce a presidência. Duas categorias de atributos do negociador podem conferir poder negocial: a autoridade ou ascendente pessoal e a sua expertise. $\mathrm{O}$ ascendente pessoal refere-se à sua personalidade, experiência prévia, estilo de liderança, capacidade de persuasão e argumentação, mas também às "visões" sobre as matérias em negociação. A expertise tem três dimensôes principais: expertise de conteúdo (conhecimento pessoal sobre a matéria em negociação), a expertise de processo (conhecimento sobre procedimentos legais, processos de tomada de decisão, poderes das várias instituições) e expertise sobre os interesses e pontos de resistência dos restantes países.

$\mathrm{Na}$ definição de Tallberg, o poder negocial é um atributo do Estado e, na operacionalização desse poder negocial, o Estado é entendido como ator único, monolítico e racional. O estudo de caso, ao usar como lente conceitual a definição de poder negocial de Tallberg, focaliza a análise no processo de negociação em si e não pretende circunstanciar o enquadramento político e econômico (nacional e internacional) em que a proposta francesa se insere. É com base nessa conceitualização que se analisa em seguida a forma como a França (não) usou os seus recursos de poder na sua iniciativa de criação da União do Mediterrâneo. Procuraremos demonstrar, ainda, que os países grandes ou "Estados fortes" da UE, em particular a França, não podem sobre-estender o seu poder negocial, negligenciando um uso equilibrado dos recursos de poder de que dispóem, sob pena de comprometerem a sua capacidade de influência sobre os resultados das negociaçôes e sobre a definição das políticas da UE. A capacidade de upload dos interesses nacionais dos Estados fortes para as políticas da UE não é algo adquirido, em particular porque os seus poderes negociais não podem ser exorbitados.

\section{O projeto de União do Mediterrâneo}

O presidente francês Nicolas Sarkozy avançou com a ideia de criação de uma União do Mediterrâneo durante a sua campanha eleitoral para a presidência da República. Desde o início de 2007 que, em vários contextos, Sarkozy menciona essa ideia e reafirma-a em outubro do mesmo ano, em Tânger, referindo-se à importância estratégica e histórica que a criação da União do Mediterrâneo tem 
para a França. ${ }^{5}$ A França iria presidir o Conselho Europeu no segundo semestre de 2008 e Sarkozy pretendia que a sua proposta contribuísse para uma maior visibilidade da sua presidência.

Ao pretender criar uma União do Mediterrâneo, o presidente Sarkozy propunha criar uma União de caráter político, econômico e cultural. No projeto inicial, previa-se que participariam como membros apenas alguns Estados da UE, nomeadamente os Estados costeiros do Mediterrâneo, que teriam estatuto de membros. Os países não situados na orla do Mediterrâneo teriam estatuto de observadores. A França argumentava que só os Estados europeus costeiros estavam interessados nesse relacionamento e só eles teriam demonstrado interesse em avançar com esse quadro de relações mais aprofundadas com o Mediterrâneo. Segundo a França, as distintas sensibilidades e interesses dos países do norte, do centro e do leste da Europa não tornavam necessário o seu envolvimento numa iniciativa relativa ao Mediterrâneo. Acrescia ainda o argumento de que só os países do sul da Europa teriam o conhecimento necessário para se envolverem nos projetos a desenvolver no âmbito dessa União.

Segundo o entendimento da França, a própria EU - e a Comissão Europeia em particular - também não estaria motivada para liderar essa iniciativa. Na opinião da França, a agenda da UE estava menos focada no Mediterrâneo e mais direcionada para as relações com os seus vizinhos do leste (Balfour e Schmid 2008; Aliboni et al. 2008). O projeto é entendido pela França como uma associação de Estados soberanos liderada pela França, de caráter intergovernamental e complementar às iniciativas plurilaterais no quadro da UE. A França propunha, assim, uma abordagem diferente - ainda que complementar - da política da UE para o Mediterrâneo, nomeadamente ao Processo de Barcelona e a Política Europeia de Vizinhança. O Processo de Barcelona, encetado sob forte influência da França e lançado em 1995 pelos Ministros dos Negócios Estrangeiros dos então 15 Estadosmembros da UE e 12 parceiros do Mediterrâneo, estabelecia o enquadramento para gerir as relações bilaterais e regionais entre esses países e constituía uma aliança destinada a criar uma zona de paz, segurança e de prosperidade partilhada. Com a Política Europeia de Vizinhança estabelecida em 2004, o Processo de Barcelona tornou-se o fórum plurilateral de diálogo e cooperação entre a UE e os parceiros do Mediterrâneo, e as relações bilaterais são geridas primordialmente no âmbito da Política Europeia de Vizinhança por meio de acordos de Associação ${ }^{6}$. A França sempre entendeu que as relações com o Mediterrâneo eram uma prioridade da UE e defende que o Processo de Barcelona, embora tivesse sido negociado e acordado

5 Alguns autores notam também que com essa iniciativa de política externa, o candidato à presidência francesa, Nicolas Sarkozy, pretendia atrair o eleitorado norte-africano na França (Aliboni et al. 2008; Tardy 2008).

6 A França sempre entendeu que as relaçōes com o Mediterrâneo eram uma prioridade da UE. No que se refere ao processo de Barcelona, tem insistido que, embora esse processo tivesse sido negociado e acordado durante a presidência espanhola de 1995, fora a presidência francesa, no semestre anterior, a responsável pelo seu lançamento, sublinhando também o papel fulcral da França para a sua materialização e conclusão. 
durante a presidência espanhola de 1995, fora lançado pela presidência francesa no semestre anterior.

Embora o papel da França para a materialização e conclusão do Processo de Barcelona tenha sido fulcral, na sua avaliação, os resultados da política da UE para o Mediterrâneo eram modestos e um novo projeto, com um envolvimento seletivo dos países da UE e paralelo às vigentes políticas da UE para o Mediterrâneo, seria mais bem-sucedido. A França preferia que as iniciativas relativas ao Mediterrâneo ficassem sob sua liderança, procurando até evitar o envolvimento da Comissão na sua gênese. O projeto foi, aliás, inicialmente apresentado como uma ruptura, uma nova experiência, em contraponto à existente política da UE para a região.

A França avançava assim com um projeto próprio, um "pet project" (Aliboni et al. 2008, 4). Segundo esses autores, o país pretendia restabelecer a sua posição de primus inter pares no Mediterrâneo. No entendimento de Sarkozy, o papel geopolítico da França na região tinha-se esbatido e importava que o país recuperasse a sua liderança com um plano sui generis de relações mais aprofundadas. Tratava-se de um projeto de integração que foi interpretado como tendo objetivos comparáveis aos da própria UE.

\section{As reações à proposta de União do Mediterrâneo}

A “visão" para o Mediterrâneo de Sarkozy, como alguns autores a apelidam, não foi nem partilhada pelos restantes Estados-membros nem pela própria UE (Balfour e Schmid 2008, 1). As fortes críticas e as inúmeras manifestaçōes de desconforto com a iniciativa surgiram desde que o projeto francês foi apresentado.

O descontentamento manifestou-se em torno de cinco questôes fraturantes: (1) os países que pertenceriam à União e (2) o envolvimento da UE, (3) a interligação do projeto com a política da UE para o Mediterrâneo, (4) a partilha dos custos envolvidos, e (5) a própria designação União do Mediterrâneo.

O principal alvo das críticas e apreensões com o projeto da União do Mediterrâneo referia-se aos países membros da UE que a constituiriam. Os restantes Estados-membros não comungaram da perspectiva da França sobre um envolvimento seletivo no projeto. Essa foi uma das matérias que levantou as mais sérias reservas não só entre os países do norte da União Europeia, mas também aos países do sul da Europa, nomeadamente à Itália e à Espanha.

Nas matérias relativas ao Mediterrâneo, esses três países eram aliados tradicionais, mas a França apresentava agora um projeto próprio, não consensualizado entre esses países. Dos países do norte da Europa provinham também fortes críticas ao projeto, pois interpretavam a iniciativa como uma forma de fazer pender para sul os interesses da UE, em detrimento do relacionamento com os países a leste da Uniāo Europeia. Emergia como consensual a posição de que nenhum país membro poderia ser excluído da política comunitária para o Mediterrâneo. A proposta 
francesa vinha pôr em causa o entendimento estratégico sobre a necessidade de equilíbrio nas prioridades da UE relativamente aos países vizinhos situados a leste e a sul da UE, ou seja, sobre o equilíbrio entre os interesses dos países comunitários do norte e do sul relativamente àquelas regióes.

Logo em dezembro de 2007, Angela Merkel rejeitou a concepção francesa de que a política da UE para o Mediterrâneo passasse a ser de participação exclusiva dos Estados costeiros. A chanceler qualificou a proposta de "perigosa" e considerou-a causadora de tensões, pois ela implicava que a ação externa da Alemanha ficaria necessariamente vocacionada para o leste da Europa enquanto à França caberia a liderança nas relaçôes com o Mediterrâneo. A Alemanha percebia a iniciativa da França como um desafio à aliança franco-germânica na UE e colocou fortes reticências à proposta, em particular quanto à "seletividade" nos membros que pertenceriam à Uniāo. Por outro lado, considerava que tampouco a própria Comissão Europeia poderia ser afastada da liderança do projeto, situação que se tinha afigurado provável dado o conteúdo da proposta que a França inicialmente apresentou. No entendimento dos restantes Estados-membros, a proposta da França configurava um projeto algo autônomo do quadro convencional de negociaçôes da UE e dos seus processos de tomada de decisão que, tal como apresentado, poderia vir a substituir as iniciativas e políticas da UE para a região, nomeadamente o Processo de Barcelona e a Política Europeia de Vizinhança.

Uma segunda linha de críticas centrava-se no fato de a proposta de União do Mediterrâneo fazer "tábua rasa" de todo o percurso da UE em matéria de relações com a região. Os Estados-membros - em particular a Alemanha, a Espanha e a Itália - entendiam que a iniciativa deveria dar continuidade às anteriores políticas e iniciativas da UE, e, nomeadamente, deveria reforçar e potencializar o Processo de Barcelona de 1995 e aproveitar o que de positivo existia na Política Europeia de Vizinhança para o Mediterrâneo de 2004. Embora reconhecessem as fragilidades destas iniciativas e políticas - que a França, no entanto, qualificava de muito negativas -, importava, no entendimento daqueles países, revitalizálas e não substituí-las por um projeto que não recuperava o acquis da UE nesse âmbito das suas relações externas. A Espanha, em particular, exerceu forte pressão para que não se desacoplasse a proposta de União do Processo de Barcelona e da Política Europeia de Vizinhança, em cuja origem tinha sido um ator central. As consequências da eventual deriva autônoma da proposta, face às políticas da UE para o Mediterrâneo, eram também temidas pelos restantes Estados-membros da UE. Em suma, os Estados-membros manifestavam forte inquietação sobre como, no plano da França, se iria articular essa Uniāo do Mediterrâneo com as competências, políticas e ações da UE para a região, em particular com o poder de iniciativa da Comissão.

A designação do projeto gerou também reações adversas entre os Estadosmembros da UE. A expressão União do Mediterrâneo evocava a criação de um processo de integração de objetivos comparáveis aos da UE e alguns temiam até 
que se tornasse num projeto de integração paralelo, e, até certo ponto, concorrente com o projeto de integração europeu.

O fato de não estar explícito quem suportaria os custos do projeto foi motivo de apreensão, pois propunha-se que apenas alguns países comunitários nele participariam. Receava-se que o orçamento da UE acabasse por ter de financiar os custos de operacionalização da iniciativa, obrigando todos os restantes membros da UE a "suportar as consequências das escolhas da diplomacia francesa" (Bechev e Nicolaidis 2008, 15). O Reino Unido manifestou-se, informando que não estaria disposto a contribuir para apoiar financeiramente as iniciativas da política externa francesa na região e essa preocupação era especialmente vocalizada pela Alemanha, que não queria vir a contribuir financeiramente para promover os interesses franceses no Mediterrâneo (Bauchard 2008, 60).

Em suma, os Estados membros pressionaram a França a enquadrar, efetivamente, a proposta no âmbito das políticas da UE para o Mediterrâneo e a aceitar inúmeras e substantivas alterações ao seu projeto.

\section{As significativas concessões da França}

O conjunto de concessões que a França teve de fazer para evitar que o seu projeto fosse rejeitado foi significativo e ilustra os limites do seu poder negocial na UE. Na mini-Cimeira de Roma de dezembro de 2007 entre França, Itália e Espanha, uma das matérias em negociação foi a participação de países da UE não mediterrânicos no projeto francês, que a França acaba por aceitar. Em março de 2008, no encontro entre a chanceler Merkel e o presidente Sarkozy, a França aceita que os países não se "dividiriam" entre países de vocação mediterrânica e não mediterrânica, e que os vários Estados-membros não teriam papéis distintos na prossecução dos objetivos da União Europeia.

Relativamente ao enquadramento da iniciativa na política da UE para o Mediterrâneo, na mini-Cimeira de Roma de dezembro de 2007, a França tem de ceder às pressóes da Itália e da Espanha para que a Comissão participasse no processo e o Conselho Europeu de março de 2008 força o envolvimento da Comissão, solicitando-lhe que apresentasse ao Conselho propostas para implementar uma União com o Mediterrâneo. Desse modo, e apesar de a Comissão não ter participado na concepção da União, a França teve de envolvê-la ativamente na reformulação do projeto e na sua implementação. A Comissão considera, em retrospectiva, que "não se poupou a esforços para apoiar a União para o Mediterrâneo" e que tem "trabalhado arduamente nos projetos adotados na Cimeira de Paris de 2008, com uma contribuição financeira substancial" (IP/09/1113). Os resultados dessa Cimeira de Paris, na qual foi lançada a União para o Mediterrâneo, decorreram das fortes pressões dos Estados-membros para que o projeto fosse reformulado e para que a Comissão participasse nessa reformulação. 
A França teve também de admitir uma inserção dos objetivos da União no âmbito do Processo de Barcelona e na Política Europeia de Vizinhança. Estabelecese que tais objetivos seriam complementares, e não viriam substituí-los nem tão pouco com eles competir, como a França inicialmente pretendia. Pelo contrário, determina-se que a União tem de reforçar os resultados do Processo de Barcelona. É de notar que os objetivos da União são os definidos para o processo de Barcelona e que se mantêm as áreas de cooperação nele já determinadas. A França vê-se, pois, compelida a integrar a União no acquis comunitário pré-existente.

É também o Conselho Europeu de março de 2008 que acaba por consagrar a designação de União para o Mediterrâneo - designação que já fora aventada na mini-Cimeira de Roma. Com essa designação pretendia-se evitar que o projeto fosse interpretado como concorrente do próprio projeto de integração da UE. De fato, no projeto finalmente aprovado, estabelece-se que a União para o Mediterrâneo não visa à integração mas, antes, se baseia no princípio da cooperação, afastando assim o receado paralelismo com o projeto de integração europeu. Acresce que a designação oficial da União é "Processo de Barcelona: União para o Mediterrâneo", clarificando-se, inequivocamente, que o Processo de Barcelona é o quadro de referência para a criação da União para o Mediterrâneo.

A França teve também que aceitar as exigências da Alemanha em matéria de financiamento do projeto. Na realidade, o que fica consagrado é que as ações a se desenvolver no âmbito da União terão não só que ser enquadradas nas prioridades previamente estabelecidas no âmbito da ajuda financeira para a Política Europeia de Vizinhança, como também não serão permitidos financiamentos adicionais da UE para implementar o projeto.

\section{Os limites do poder negocial da França}

O projeto da França de criação da União do Mediterrâneo era ambicioso e o governo francês estava fortemente motivado para concretizá-lo (Emerson 2008). A França detinha todos os recursos de poder identificados por Tallberg. É um país com fortes recursos de poder estrutural na União Europeia: é o maior país da UE em extensão, o segundo em população e que tem o segundo maior PNB da UE; por razões históricas, econômicas e culturais, tem poder específico na negociação de assuntos relativos ao Mediterrâneo. Adicionalmente, a França usou a presidência da UE para exercer o seu poder institucional e avançar com uma proposta que procurava fundamentalmente satisfazer o seu interesse nacional e reafirmar a sua influência na região. A combinação desses recursos de poder levou-a a negligenciar algumas das dimensões de poder estrutural na UE. Usou o poder da presidência para colocar o Mediterrâneo na agenda da UE e recorreu ao poder negocial individual de Sarkozy (ascendente pessoal, expertise de conteúdo e processo) para apresentar uma iniciativa que espelhava fundamentalmente 
os interesses da França. Descurou, porém, a importância dos contatos prévios com os restantes países da UE para identificar interesses comuns e pontos de resistência à sua proposta, requisitos essenciais para a criação de entendimentos. $\mathrm{O}$ conhecimento das preferências dos negociadores é pré-requisito para fazer alianças e coligações e para conduzir a negociação. No caso em apreço, a França não o fez e a inexistência de entendimentos prévios com os outros Estados-membros acabou por comprometer, de forma fundamental, os objetivos iniciais da França. A França não adotou uma estratégia de negociação integrativa, focada nos interesses comuns dos Estados-membros da UE, criadora de valor (Raiffa 1982), apostada em identificar, alargar e agir em torno dos interesses comuns (Elgstrom e Jönsson 2000). A inexistência de uma estratégia negocial integrativa desde o início do processo foi interpretada como uma pretensão da França em criar um projeto de caráter nacional destinado a reforçar, unilateralmente, a sua presença na região. A França descurou a expectativa dos restantes países da UE de que seriam ouvidos no processo de criação da União, audição a que se sentiam com direito. A sua condução do processo negocial fez com que a iniciativa fosse interpretada como um projeto cujos objetivos o colocavam, de algum modo, "à margem” das políticas europeias e não apenas uma tentativa de fazer o upload dos interesses nacionais Franceses para a política europeia para o Mediterrâneo. A falta de cooperação inicial com os restantes Estados-membros e com a Comissão era evidência, para muitos países, de que a França pretendia distanciar-se das iniciativas da UE para o Mediterrâneo. Embora a administração francesa insistisse que a sua iniciativa poderia até trazer mais coerência e mais abrangência às políticas da UE, a União do Mediterrâneo não foi assim percebida. Pelo contrário, ela era lida como uma sobreposição às diferentes dimensões da política da UE para a região.

Mas foram também outros os erros cometidos pela França na apresentação do seu projeto, os quais motivaram fortes reações dos restantes países da União Europeia. Essas reaçôes obrigaram-na a rever fundamentalmente a proposta inicial, ao ponto de ficar fortemente desvirtuada face aos objetivos que tinham sido enunciados em 2007. Antevia-se, logo no final de 2007, que as pretensóes francesas iriam sofrer fortes reveses e que o projeto seria profundamente alterado. Como referem Balfour e Schmid $(2008,2)$ a França procurou consensos "ex post" e com tal estratégia acabou por ficar impossibilitada de concretizar o projeto nos moldes que tinha ambicionado, mas também ficou impedida de desistir da sua criação. Na verdade, procurar estabelecer um projeto sem o envolvimento e apoio dos dois outros países que sempre lideraram a política da UE para o Mediterrâneo era comprometer o seu sucesso. Nessa negociação, a França preferiu não seguir o princípio de enlightened self-interest (Rubin 1989), que estabelece que a definição dos interesses negociais deve ter por base o interesse individual mas também os interesses e expectativas dos parceiros negociais. 
Segundo Balfour e Schmid (2008, 1), os franceses não estavam preparados para a forte oposição ao projeto, e a França teve sucessivamente que redimensioná-lo. No início, no entanto, procurou desvalorizar e justificar as reações negativas à iniciativa, procurando passar a ideia de que os Estados-membros, embora agastados com os objetivos e os contornos do projeto, estavam a convergir para a proposta francesa. A título de exemplo, o fato de a Espanha ter proposto a Sarkozy em dezembro de 2007 acompanhá-lo na apresentação do projeto aos futuros parceiros do Mediterrâneo foi usado pela França para comprovar a sua tese. No entanto, constatou-se que a estratégia da Espanha era, pelo contrário, poder acompanhar e participar na iniciativa, para garantir a continuidade do Processo de Barcelona.

Sobre as reações dos países do norte da UE e a necessidade de implementar um projeto para o Mediterrâneo com essas características, a França sublinhava que tinha de realizar um "trabalho pedagógico" (Bauchard 2008, 60) de forma a convencê-los que a fratura do Mediterrâneo afetava os seus interesses e a sua segurança. Mas a questão do convencimento dos países do Norte sobre a importância estratégica do Mediterrâneo não se colocava. Como referem Aliboni et al. $(2008,29)$, a distinção entre o interesse e motivação dos países europeus do Mediterrâneo e o desinteresse dos países não mediterrânicos na região é inapropriada, até porque a Alemanha e a Suécia apoiaram o processo de Barcelona desde o seu início. Os países do norte da Europa reagiam porque tal União não poderia apenas ser constituída por um subgrupo de países da UE.

A ambição excessiva da França ao procurar colocar o seu projeto, de alguma forma, fora do espaço negocial (Odell 2001; Woolcock 2003) da União Europeia e os fatos de não ter usado de forma equilibrada os recursos de poder de que dispunha e de ter "sobreusado" outros poderes (nomeadamente o poder estrutural agregado, o poder específico ao assunto e o poder do negociador, Nicolas Sarkozy) comprometeram os seus objetivos iniciais. A proposta de União do Mediterrâneo partia do pressuposto de que um Estado forte como a França poderia alcançar os seus objetivos. Contudo, tal como este estudo de caso evidencia, o poder negocial dos países grandes da UE, e da França em particular, tem limites, tem de ser usado com sentido de equilíbrio e não pode ser "sobre-estendido".

Tratando-se de um Estado forte, e tendo em conta o seu poder negocial, a França conseguiu alguns dos seus objetivos iniciais. Conseguiu colocar a relação da UE com o Mediterrâneo entre as prioridades externas da UE, não só durante a sua presidência mas também no período que a antecedeu. Algumas das suas estratégias negociais foram também calculadas. Pelo fato de ter tomado a iniciativa de criação da União, a França optou por uma estratégia de first mover, a qual fez com que os restantes países da UE ficassem limitados a fazer ajustamentos à sua proposta; ao envolverem-se no processo, o seu papel foi de "damage control" (Balfour e Schmid 2008), procurando reformular uma proposta previamente apresentada e na qual não tinham participado de raiz. Interessantemente, a França conseguiu 
também associar a sua iniciativa ao lema "Uma União de projetos para um projeto de Uniāo" a constituir-se.

\section{Referências bibliográficas}

ALIBONI, Roberto, DRISS, Ahmed, SCHUMACHER, Tobias e TOVIAS, Alfred. (2008) Putting the Mediterranean Union in Perspective. Euromesco Paper, no 68.

BAUCHARD, Denis. (2008) L'Union pour la Méditerranée: un défi européen. Politique Étrangère, Vol. 1, p. 51-64.

BALFOUR, Rosa. e SCHMID, Dorothée. (2008) Union for the Mediterranean, disunity for the EU? Policy Brief, Center for European Policy Studies, February.

BECHEV, Dimitar e NICOLAIDIS, Kalypso. (2008) The Union for the Mediterranean: A Genuine Breakthrough or More of the Same?'The International Spectator, Vol. 43, n 3, p. 13-20.

DUR, Andreas e MATEO, Gemma. (2008) Bargaining Power and Negotiation Tactics: Negotiations on the UE's Financial Perspective, 2007-2013. DEI Working Paper 08-2, UCD Dublin European Institute.

ELGSTROM, Ole. e JÖNSSON, Christer. (2000) Negotiation in the European Union: bargaining or problem-solving? Journal of European Public Policy, Vol. 7, no 5, p. 684-704.

EMERSON, Michael. (2008) Making sense of Sarkozy's Union for the Mediterranean. Policy Brief, Center for European Policy Studies, March, no 155.

HABEEB, William M. (1988) Power and Tactics in International Negotiation: How Weak Nations Bargain with Strong Nations. Baltimore, John Hopkins University Press, 182 p.

ODELL, John. (2001) Negotiating the World Economy. Ithaca, Cornell University Press, 272 p.

RAIFFA, Howard. (1982) Art and Science of Negotiation. Harvard, Harvard University Press, 384 p.

RUBIN, Jeffrey Z. (1989) Some Wise and Mistaken Assumptions about Conflict and Negotiation. Journal of Social issues, Vol. 45, nº 2, p. 195-209.

TALLBERG, Jonas. (2008) Bargaining Power in the European Council. Journal of Common Market Studies, Vol. 46, no 3, p. 685-708.

TARDY, Vladimir, (2008) “L’Union pour la Méditerranée”, une des priorités de la Présidence Française de l'Union Européenne”. Centre d'Études et de Recherches Internationales. []. Disponibilidade: 1/09/2011.

WOOLCOCK, Stephen. (2003) “Theoretical Analysis of Economic Diplomacy”. In Bayne, Nicholas e Stephen Woolcock, Eds., The New Economic Diplomacy. Decision-Making and Negotiation in International Economic Relations. Aldershot, Ashgate. 314 p.

Recebido em 26 de setembro de 2011 Aprovado em 15 de dezembro de 2011

7 Itálico da autora. 


\title{
Resumo
}

A partir de um estudo de caso sobre a iniciativa da França de criação de uma União do Mediterrâneo, o artigo testa a hipótese de que de que os "grandes" Estados da União Europeia, embora concentrando importantes recursos de poder negocial, comprometem significativamente os seus objetivos negociais se sobre-estenderem esses poderes.

Palavras-chave: França; Mediterrâneo; poder negocial; União Europeia.

\begin{abstract}
Using a case study on France's initiative to create a Union of the Mediterranean, this article tests the hypothesis that the "largest" states of the European Union, though concentrating major sources of negotiating power, significantly jeopardize their negotiating objectives if they overstretch their negotiating power.
\end{abstract}

Keywords: France; Mediterranean; negotiating power; European Union. 